\title{
Telemedicine/telehealth in Preventive Medicine
}

\author{
Burçin Yıldırım $^{1}$ (D), Muhammed Mustafa Uzan ${ }^{2}$ (D), Memet Taşkın Egici ${ }^{3}$ (D), \\ 1 Kastamonu Tosya Public Hospital, Department of Family Medicine, Kastamonu, Turkey \\ 2 Health Sciences University, İzmir Tepecik Training and Research Hospital Department of Family Medicine, İzmir, Turkey \\ 3 Health Sciences University, İstanbul Haydarpaşa Numune Training and Research Hospital Department of Family Medicine, İstanbul, Turkey
}

\begin{abstract}
Telemedicine describes the remote medical support that the patients receive from physicians for their health. Telehealth, on the other hand, covers all subjects such as patient education, diagnosis, treatment, raising awareness about health issues, and includes mobile health as well as telemedicine. Preventive medicine describes practices and approaches to prevent undesirable situations and complications before, during, or after the occurrence of diseases.

Primary care providers, who practice preventive medicine most intensively, also frequently exercise telehealth practices. Costeffectiveness, data security, addressing the lack of education of patients and doctors, redesigning computer systems in terms of ease of use, making necessary legal regulations, and simplifying bureaucratic duties create concerns for physicians and users.

Since physical contact with the patient is not possible, communication between the doctor and the patient should be maintained simultaneously through technological methods. Therefore, the existing infrastructure, internet network, and hospital data system should be both fast, and near-perfect. Telemedicine may be a very good alternative for patients, assuming that healthcare institutions are largely concerned with pandemic patients, or that the risk of Covid-19 has not yet been eliminated in hospitals.
\end{abstract}

Keywords: Telehealth, Telemedicine, Preventive Medicine, Covid-19, Mobile Health. 


\section{INTRODUCTION}

With the introduction of the coronavirus pandemic (Covid-19) into our lives, both remote working and its principles have become widespread and gained prominence in the new world order. The success of remote working practices in many areas brought up the widespread usage of these practices in the healthcare sector. In this review, the use of telemedicine/telehealth in preventive medicine practices and new developments that emerged with the Covid-19 pandemic will be discussed in light of the current literature.

Telemedicine describes the remote medical support that the patients receive from physicians for their health. Telehealth, on the other hand, covers all subjects such as patient education, diagnosis, treatment, raising awareness about health problems, and includes mobile health as well as telemedicine $(1,2,3)$.

It is known that there are many approaches to telemedicine. It is stated that the first use of telemedicine was a warning system based on smoke communication regarding an epidemic disease. To give an example from the recent period, it is stated that in 1999, a patient in Antarctica shared the lump in her breast via satellite, she was diagnosed with cancer, and then chemotherapy agents parachuted to the station (4).

On behalf of telemedicine, for the first time in our country, it was ensured that the images of radiological examinations were on a web environment that could be accessed continuously, that these images were reported and that they could be accessed by citizens or physicians via the e-Nabiz application. Later, laboratory results were integrated into this system. In this way, physicians' work has been facilitated and repetitive examination requests have been prevented (5). Recently, the webbased application 'Neyim Var' developed by the Ministry of Health within the scope of mobile use was made available to patients (6).

One of the topics to be discussed within the framework of Telemedicine/Telehealth is the billing issue. In Turkey, departments such as Gastroenterology, General Surgery, Psychiatry, and Family Medicine under Kocaeli University Faculty of Medicine, already provide telemedicine services under the name of "web clinics". However, there is no clear data on how these examinations will be billed or how they will be controlled by health institutions (7).

Another important issue is how much medical malpractice insurance will be included in this system. As the recently - increased malpractice cases and the high compensations have often led physicians to defensive medicine, telemedicine can raise new questions. The "Framework for the Implementation Procedures and Principles of TeleHealth Service" issued in 2015 specifies the procedures and principles for medical services only for aircraft and sea vehicles cruising within the Turkish Search and Rescue Area. In February 2021, the General Directorate of Health Information System of the Ministry of Health attempted to create a system called "dr.e.nabiz" and even a user guide was published. However, due to unknown reasons, the system was not implemented. Therefore, although new steps have been taken in this regard, there are uncertainties in terms of both applicability and establishing a legal basis (7).

Table 1. WHO has identified five specific categories of telemedicine practices (8)

\begin{tabular}{|c|c|}
\hline Teleradiology & $\begin{array}{l}\text { Use and interpretation of digital } \\
\text { radiology. }\end{array}$ \\
\hline Teledermatology & $\begin{array}{l}\text { Conveying and consulting medical } \\
\text { information and images related to } \\
\text { the skin. }\end{array}$ \\
\hline Telepathology & $\begin{array}{l}\text { Diagnostic consultation of pathology } \\
\text { preparation image sections. }\end{array}$ \\
\hline Telepsychiatry & $\begin{array}{l}\text { Remote delivery of mental health } \\
\text { services. }\end{array}$ \\
\hline $\begin{array}{l}\text { Remote patient } \\
\text { monitoring } \\
\text { (Monitorization) }\end{array}$ & $\begin{array}{l}\text { Monitoring the health status of } \\
\text { patients with restricted mobility or } \\
\text { limited access with cameras, sensors, } \\
\text { mobile applications, and various } \\
\text { devices. }\end{array}$ \\
\hline
\end{tabular}

Preventive medicine describes practices and approaches to prevent undesirable situations and complications before, during, or after the occurrence of diseases (9). Prevention consists of levels called primordial, primary, secondary, tertiary, and quaternary prevention. Primordial prevention includes preventive services for the general 
population. Water sanitation and tobacco control can be given as examples of this practice. Primary prevention refers to practices for the prevention of diseases for a particular risk group. Pneumococcal vaccination in adults is an example of this practice. Secondary prevention covers early diagnosis and treatment applications. Cancer screenings would be an example in this regard.

Tertiary prevention avoids undesirable situations and complications that may develop after the disease occurs. Rehabilitation of a stroke patient is an example of tertiary prevention. Quaternary prevention is "a practice to identify patients and communities at risk of overmedicalization, protect them from medical invasions, and provide them with scientifically and ethically acceptable care procedures". Avoiding exposing the person to excessive radiation for examination purposes is quaternary prevention (10). In this context, primary care providers who practice preventive medicine most intensively, also frequently exercise telehealth practices.

In Spain, telemedicine practices can also be carried out in primary care. In a study conducted here, it was concluded that the physicians are satisfied in terms of cost-effectiveness, but the lack of training of patients and physicians should be eliminated as well as the lack of data security, and computer systems should be redesigned to provide ease of use. In addition, participating physicians expect necessary legal regulations to be made and simplify their bureaucratic duties. Patients participating in the same study expressed their concerns about data security (11).

Again, in Australia, primary care physicians stated that they are in need of training and technical support regarding telehealth. In the study carried out in this region, the participants emphasized that there should be software integrated into their existing systems and that network connections should be developed. (12).

In Sweden, the experiences and care patterns of people receiving telemedicine services from primary health care providers were examined. According to this examination, the participants of the study conducted in Sweden stated that they are satisfied with the high accessibility. In addition, a decrease in consulting primary care and emergency departments was observed (13).
In a 2015 study conducted in the United Kingdom with 21 subjects from nursing homes without the telemedicine system and 27 more from ones with the system installed, it was found that in 20 months, the rate of consulting emergency departments decreased by $45 \%$, and the costs of consulting healthcare providers decreased by $39 \%$ (14).

In a randomized controlled study conducted in the USA in 2020, it was found that medication compliance was 7 times higher in patients discharged from the hospital and followed up with a telehealth system for 12 months. No significant difference was observed between the rates of consulting emergency departments and hospitalization of the patients (15).

In a US-based study conducted with chronic obstructive pulmonary patients in which physical frailty was remotely monitored, patients admitted to the telehealth pulmonary rehabilitation clinic and the control group were examined based on elbow flexion and arm extension strength. Sensitivity was found to be high in monitoring physical frailty in both groups using the sensor-based system and camera-based telehealth system. It was seen that physical fragility could be monitored remotely by using a twodimensional and high-resolution camera (16).

Society needs to use telehealth applications as well as health professionals. In the mobile health (mHealth) study conducted in the USA in 2019, the blood pressure and heart rate of the participants were measured for 12 weeks with the help of an application downloaded to their mobile phones and smartwatches. As a result of the study, an e-cohort identifies cardiovascular disease risk factors were defined. In addition, it was detected that the participants were highly compatible with the monitoring of cardiovascular parameters with a smartwatch (17).

The study conducted in Japan, in which patients with fatigue complaints were examined, is an alternative. Changes after personalized nutritional therapy based on remote blood data analysis were screened by the Anti-Aging QOL Common Questionnaire published by the Japanese Society of Anti-Aging Medicine. Ferritin, total protein, albumin, blood urea nitrogen, creatinine, total cholesterol, high-density lipoprotein cholesterol (HDL), triglyceride (TG), aspartate aminotransferase (AST), alanine aminotransferase (ALT), $\gamma$-glutamyl 
transpeptidase $(\gamma$-GTP), alkaline phosphatase (ALP), lactate dehydrogenase (LDH), cholinesterase, creatine kinase (CK) and mean corpuscular volume (MCV) levels of patients were analyzed in the study. Before and after nutritional therapy, symptoms were followed up in 3-month periods using the questionnaire with telehealth application. After the treatment, a significant change was observed especially in the complaints of fatigue of the patients. Vitamin supplements and mineral supplements were used in nutritional therapy. Patients whose complaints did not regress were referred for medical treatment (18).

In cases where physical contact with the patient is not possible, the communication between the doctor and the patient should be maintained simultaneously through technological methods. Therefore, the existing infrastructure, internet network, and hospital data system should be both fast and near - perfect. Telemedicine may be a very good alternative for patients, assuming that healthcare institutions are largely concerned with pandemic patients, or that the risk of Covid-19 has not yet been eliminated in hospitals. For this reason, hospitals in many countries are trying to provide help for diseases that will require green zone examination through the telemedicine system (19).

Even if the entire infrastructure is complete, there will of course be communication problems. In a study conducted by Eberly et al. on the use of telemedicine during the Covid-19 pandemic, telemedicine has been found to be used at lower levels by elderly patients, Asian patients, and non-English speaking patients in the early days of Covid-19. Likewise, it was determined that telemedicine is used by female patients, African - American patients or patients of Hispanic origin, and patients with low socioeconomic status at lower levels (20).

Bolivia is one of the countries where remote monitoring of Covid-19 patients is carried out along with the pandemic. According to the data of the National Call Center, a low mortality rate was observed in patients who received teleconsultation. It could be seen in the data that the burden of the health system is alleviated when remote monitoring is done effectively (21).
Similar results were also obtained in Brazil. It was reported that as a result of the follow-up of Covid-19 patients using telehealth, resources are used effectively, and inequality of access is reduced. The biggest concern of Brazilian doctors when providing teleconsulting services was asymptomatic cases (22).

In Australia, the body temperature, heart rate, and oxygen saturation of Covid-19 patients without active comorbid disease and who can be treated at home or in other suitable places were monitored. No deaths were observed in the cases followed up. Telehealth applications have been effective in meeting health needs during the pandemic and have greatly prevented the healthcare systems from straining. Healthcare providers must anticipate problems with data transfer and develop strategies that can increase people's access to telehealth technologies (23).

\section{CONCLUSION}

Today, telehealth is generally used in the follow-up process of patients and is seen as a complementary rather than an alternative to physical rounds. In the light of these observations on Telehealth or Telemedicine, it has been seen that this system is useful. However, how and/or in which situations this system can be used needs to be discussed.

You will appreciate that taking advantage of this method, especially during the pandemic, will also alleviate the burden of the healthcare system. However, we believe that necessary legislative arrangements should be made in this regard, algorithms should be created for the follow-up of patients to be included in the telehealth system, information systems should be optimized and the necessary network infrastructure should be provided.

On the other hand, for the effective use and dissemination of these applications, the legal authorities and responsibilities of all healthcare professionals, especially physicians, regarding their transactions within the scope of telehealth, and also the rights and responsibilities of service recipients should be determined. 


\section{REFERENCES}

1. World Health Organization. Telemedicine - Opportunities and developments in Member States. Available at: https: / / www.who.int/ goe/publications/goe_telemedicine_2010.pdf Accessed November 27, 2021.

2. U.S. Department of Health and Human Services. Finding telehealth options. Available at: https://telehealth.hhs.gov/patients/findingtelehealth-options / Accessed November 27, 2021.

3. Medlineplus. Telehealth. Available at: https://medlineplus.gov/ telehealth.html Accessed November 27, 2021.

4. Waller M, Stotler C. Telemedicine: a primer. Curr Allergy Asthma Rep. 2018;18(10):54.

5. Sungur, C. Teletıp uygulamalarında hasta memnuniyeti: bir sistematik derleme çalışması. Hacettepe Sağlık İdaresi Dergisi, 2020;23(3):505-522

6. T.C. Ministry of Health. Neyim var. Available at: https://neyimvar. gov.tr/tr/ Accessed November 29, 2021.

7. Dilbaz, B. Kaplanoğlu, M. Kaya, D. Teletıp ve telesağlık: Geçmiş, bugün ve gelecek. Eurasian Journal of Health Technology Assessment, 2020;4(1):40-56

8. Doğramacı YG. Teletıp, sağlık turizmi ve uzaktan sağlık hizmetleri: Mesafeli sözleşmeler. İstanbul Hukuk Mecmuası 2020;78(2):657-710.

9. Clarke EA. What is preventive medicine? Can Fam Physician 1974;20(11):65-68.

10. Pandve HT. Quaternary prevention: need of the hour. J Family Med Prim Care. 2014;3(4):309-10.

11. Cernadas Ramos A, Bouzas-Lorenzo R, Mesa Del Olmo A, Barral Buceta B. Opinion of doctors and users on e-health advances in primary care. Aten Primaria. 2020;52(6):389-399.

12. Hanna L, Fairhurst K. Using information and communication technologies to consult with patients in Victorian primary care: the views of general practitioners. Aust J Prim Health. 2013;19(2):166-70.

13. Gabrielsson-Järhult F, Kjellström S, Josefsson KA. Telemedicine consultations with physicians in Swedish primary care: a mixed methods study of users' experiences and care patterns. Scand J Prim Health Care. 2021;39(2):204-213.

14. Hex N, Tuggey J, Wright D, Malin R. Telemedicine in care homes in Airedale, Wharfedale and Craven. Clin Govern Int J. 2015;20:146-154

15. Noel K, Messina C, Hou W, Schoenfeld E, Kelly G. Tele-transitions of care (TTOC): a 12-month, randomized controlled trial evaluating the use of Telehealth to achieve triple aim objectives. BMC Fam Pract. 2020;21(1):27.

16. Zahiri M, Wang C, Gardea M, Nguyen H, Shahbazi M, Sharafkhaneh $\mathrm{A}$, et al. Remote physical frailty monitoring-the application of deep learning-based image processing in tele-health. IEEE Access. 2020;8:219391-219399.

17. McManus DD, Trinquart L, Benjamin EJ, Manders ES, Fusco K, Jung LS, et al. Design and preliminary findings from a new electronic cohort embedded in the Framingham heart study. J Med Internet Res. 2019;21(3):e12143.

18. Arakaki M, Li L, Kaneko T, Arakaki H, Fukumura H, Osaki C, et al. Personalized nutritional therapy based on blood data analysis for Malaise patients. Nutrients. 2021;13(10):3641.

19. Portnoy J, Waller M, Elliott T. Telemedicine in the era of COVID-19. J Allergy Clin Immunol Pract. 2020;8(5):1489-1491.

20. Eberly LA, Kallan MJ, Julien HM, Haynes N, Khatana SAM, Nathan AS, et al. Patient characteristics associated with telemedicine access for primary and specialty ambulatory care during the COVID-19 pandemic. JAMA Netw Open. 2020;3(12):e2031640.
21. Nina-Mollinedo JM, Quesada-Cubo V, Rivera-Zabala L, MirandaRojas SH, Olmos-Machicado JR, Arce-Alarcon N, et al. Hundred days of teleconsultations and their usefulness in the management of Covid-19: Experience of the Covid-19 national call center in Bolivia. Telemed J E Health. 2021; Ahead of print: doi: 10.1089/tmj.2021.0250.

22. Montelongo A, Becker JL, Roman R, de Oliveira EB, Umpierre RN, Gonçalves MR, et al. The management of Covid-19 cases through telemedicine in Brazil. PLoS One. 2021;16(7):e0254339.

23. Hutchings OR, Dearing C, Jagers D, Shaw MJ, Raffan F, Jones A, et al. Virtual health care for community management of patients with Covid-19 in Australia: Observational cohort Study. J Med Internet Res. 2021;23(3):e21064. 